\title{
Post-vaccination survey for monitoring the side effects associated with COVID-19 vaccines among healthcare professionals of Jazan province, Saudi Arabia
}

Waquar Ahsan, PhD, Nabeel K. Syed, MS, Aseel A. Alsraeya, PharmD student, Hassan A. Alhazmi, PhD, Asim Najmi, PhD, Mohammed Al Bratty, PhD, Shamama Javed, PhD, Hafiz A. Makeen, PhD, Abdulkarim M. Meraya, PhD, Ahmed A. Albarraq, PhD, Saad S. Alqahtani, PhD.

\begin{abstract}
الأهداف : الرصد الذاتي لأثار اللقاح الجانبية على مستوى مهن الرعاية الصحية في المباء

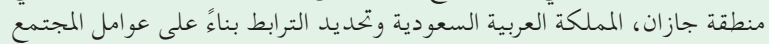
و السكان.

المنهجية : بمجموع 397 ممارس صحي من منطقة جازان وتمت المتبد المشاركة بدون

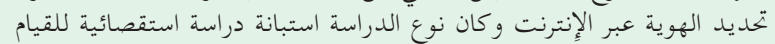

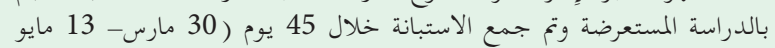

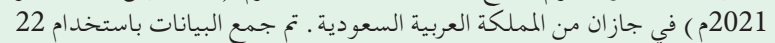
أداة تحقق من خلال التقرير الذاتي للدراسة الاستية المتعصائية .

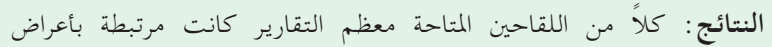

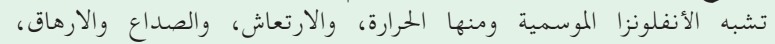

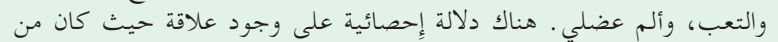

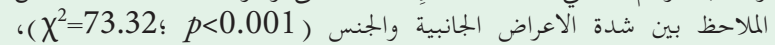

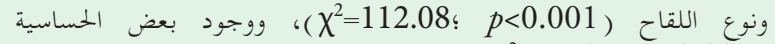

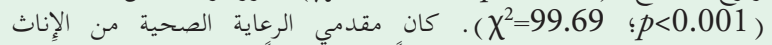

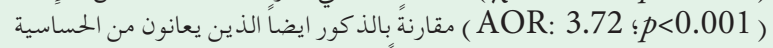

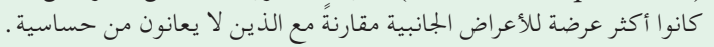

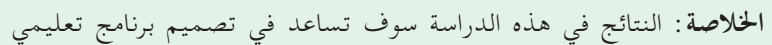

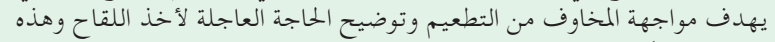

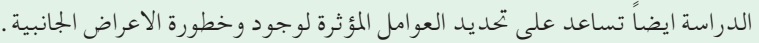

Objectives: To identify the self-reported vaccine-related side effects among healthcare professionals ( $\mathrm{HCPs}$ ) in the Jazan province, Saudi Arabia, and determine the associated socio-demographic factors. With the recent second and third waves of coronavirus disease -19 (COVID-19) infections worldwide, the race is not only to encourage but also to achieve mass vaccination.

Methods: A total of 397 HCPs from across Jazan province participated in an anonymous online cross-sectional survey conducted for a period of 45 days (March 30, 2021 to May 13, 2021) in Jazan province, Saudi Arabia. Data was collected using a validated 22 -items self-report survey.
Results: For both COVID-19 vaccines, majority of reports were related to flu-like symptoms including fever, chills, headache, fatigue, tiredness, and myalgia. Statistically significant associations were observed between the severity of side effects and gender $\left(\chi^{2}=73.32 ; p<0.001\right)$, type of vaccine $\left(\chi^{2}=112.08 ; p<0.001\right)$, and presence of known allergies $\left(\chi^{2}=99.69 ; p<0.001\right)$. Female HCPs were more likely to report any side effects compared with male HCPs (adjusted odds ratio [AOR]: 3.72; $p<0.001$ ). Furthermore, HCPs with known allergies were more likely to report any side effects than their counterparts with unknown allergies (AOR: 16.29; $p<0.001$ ).

Conclusion: The findings of the present study would help in designing educational programs aimed at combating the misconstrued fear of vaccination and highlighting the urgent need of getting vaccinated. This study also helps in the identification of factors affecting the presence and severity of side effects.

Keywords: COVID-19 vaccinations, covishield, AstraZeneca, Pfizer-BioNTech, side effects, Saudi Arabia

Saudi Med J 2021; Vol. 42 (12): 1341-1352 doi: 10.15537/smj.2021.42.12.20210576

From the Department of Pharmaceutical Chemistry (Ahsan, Alhazmi, Najmi, Al Bratty); from the Department of Pharmaceutics (Javed), College of Pharmacy; from the Pharmacy Practice Research Unit (Syed, Makeen, Meraya, Albarraq, Alqabtani), Department of Clinical Pharmacy; from the College of Pharmacy (Alsraeya); and from the Substance Abuse and Toxicology Research Centre (Alhazmi), Jazan University, Jazan, Kingdom of Saudi Arabia.

Received 5th July 2021. Accepted 2nd November 2021

Address correspondence and reprint request to: Dr. Waquar Ahsan, Department of Pharmaceutical Chemistry, College of Pharmacy, Jazan University, Jazan, Kingdom of Saudi Arabia. Email:wmohammad@jazanu.edu.sa

ORCID ID: https://orcid.org/0000-0002-5987-2933 
$A^{s}$ the ongoing pandemic caused by severe acute respiratory syndrome-coronavirus-2 (SARS-CoV2) entered its second year, an increasing number of people have been affected across the world.,2 The vigilance around physical distancing, wearing masks, public health interventions, and social gatherings has eased off, and some countries have been hit by second and third waves due to their hasty easing off of spatial distancing measures. ${ }^{3}$ Furthermore, the emergence of novel mutated viral variants has played a role in the rampant increase in the number of infected cases. With no clear global consensus on the treatment guidelines of coronavirus disease -19 (COVID-19) and treatment being rendered on a case-to-case basis, immunization with the currently approved vaccines remains the only way to fight the pandemic and curb the morbidity and mortality associated with it. All the countries are in a race against time to vaccinate their citizens and residents in the quickest possible ways.

A number of COVID-19 vaccines have been rolled out around the world, and different countries have granted emergency approvals to varying vaccines to be used on their population. ${ }^{4,5}$ To date, the Saudi Food and Drug Authority (FDA) has approved 2 vaccines, (namely, Pfizer BioNTech and Oxford-AstraZeneca) to be used on its population. Although the efficacies of both vaccines have shown to be promising in clinical trials, information on their safety in real-world settings remains scarce. ${ }^{4}$ The recent news on the incidence of some serious adverse effects such as thrombosis being reported in Austria and Denmark upon administration of the Oxford-AstraZeneca vaccine has made matters worse and increased the fear of vaccinations among the masses. ${ }^{6}$ For this very reason, post-vaccination surveillance of the vaccines being used is imperative.

This survey aimed to assess the post-vaccination side effects upon the administration of the COVID-19 vaccine in Jazan Province, Saudi Arabia. Healthcare professionals (HCPs) were selected as the target population because they have a better understanding of the type and severity of side effects and their associated medical conditions as compared with the general population.

Methods. The data was collected using an anonymous online cross-sectional survey carried out from March 30, 2021 to May 13, 2021 (45 days) in

Disclosure. Authors have no conflict of interests, and the work was not supported or funded by any drug company. the Jazan provice, Saudi Arabia. The self-report survey was prepared using Google Forms. The invitation link for participating in the current study was circulated on various platforms of social media (Twitter, Facebook, WhatsApp, Instagram, etc.) among male and female HCPs. Snowball convenience sampling was used for sample recruitment. Male and female HCPs who were residents of Jazan province, above the age of 26 years, who had received at least one dose of either the Pfizer BioNTech or Oxford-AstraZeneca vaccine, had a good understanding of Arabic or English languages, willing to participate in the study, willing to complete the survey, and willing to provide informed consent were included in the study. All other respondents not fulfilling the eligibility criteria were excluded from the study.

The literature search to find prior related research was conducted during January-February 2021 and the relevant keywords (COVID-19 vaccines, side effects, Saudi Arabia) were used on search databases Pubmed and Scopus. Recent literature pertaining to the side effects of COVID-19 vaccines in Saudi Arabia and in other parts of the world was studied.

A structured, validated, and pre-coded self-report survey was used for data collection. The survey comprised 2 sections (Appendix 1). Section one comprised 6 questions regarding the sociodemographics of the respondents. Section 2 consisted of 16 questions asking the respondents on their current medical conditions, the type and number of doses of vaccine received, and the type and severity of side effects experienced. The questionnaire was developed for this study by the authors based on the questions asked on the Saudi-FDA and Centers for Disease Control and Prevention (CDC) official websites used for reporting COVID-19-related side effects. ${ }^{8,9}$ Participants of the present study reported their gender, age (in years), nationality, education, occupation, city of current residence, and marital status, which were used as explanatory variables. The participants also reported the name of the vaccine received, doses of the vaccine received, comorbidities/current medical history, known allergies, current medications, and the presence and severity of side effects experienced. The time after which the participants experienced the side effects, need for medical assistance for the treatment of those side effects, and time taken to completely recover were also asked from the respondents. All the questions in section 2 sought to identify the presence of side effects experienced post-vaccination and their relationship with medical and non-medical factors. Most of the questions had a binary (yes/no) response, except for questions regarding the timeline after which side effects were reported $(<12$ 
hours (h) / 12-24 h / 24-48 h / >48 h), after which dose these side effects were reported (first/second), the severity of the side effects (no side effect/minor side effects/major side effects), and the time taken for a full recovery (1-2 days / >2 days).

After careful deliberation, the initial English draft of the survey was prepared by the authors. A 6-member independent experts committee comprising experienced and skilled pharmacists, physicians, and nurses was constituted for reviewing the survey instrument. The survey instrument was validated by content and face validation. The 6-member experts committee evaluated the content validity of the questionnaire. The clarity as well as relevance of every item of the questionnaire was evaluated by determining their item content validity index (I-CVI). It was reported that the minimum requirement for validation is an $\mathrm{I}-\mathrm{CVI} \geq 0.78$ with at least 3 of the experts. ${ }^{10,11}$ Any item with an I-CVI $<0.78$ for relevance was consequently deleted from the questionnaire. The final version of the survey comprised questions spread across 2 sections. The survey instrument was translated using forward-backward translation. ${ }^{12}$ An expert professional bilingual translator who was fluent in English and Arabic was asked to translate the questionnaire into Arabic, which was further reviewed by an author with bilingual fluency (Arabic and English). Any discrepancies, if present, were then discussed with the professional translator and resolved, after which a final version was prepared and approved. Another author having similar bilingual fluency and who was until then kept unaware of the initial English version of the survey instrument then back-translated the approved final Arabic version into English. Lastly, the forward and backward translated versions were reviewed thoroughly among the authors. The ease of use and the completion time were assessed by conducting a pilot study in a focus group of 39 study participants, and the questions elicited appropriate responses without any difficulty in answering and analyzing the data. ${ }^{13}$ Around 10 min was noted to be the average completion time, and all the participants reported understanding the questions with relative ease.

An anonymous online survey was used for data collection. Informed consent was obtained online prior to data collection. The study participants were required to select "yes" for an obligatory question seeking their consent. The participants could only progress to the other sections of the questionnaire after providing their consent. A "no" response would automatically end the survey, and the response was considered a dropout. Inability of the participants to complete any section or any question rendered the response as incomplete and was then consequently removed from the statistical analysis during validation of the responses. A $97.3 \%$ response rate (397/408) was found in the current study. The sample size of this study was determined using Raosoft sample size calculator. A sample size of 384 was determined on the basis of a $95 \%$ confidence interval (CI), 5\% margin of error, approximate target population of 150,000 , and response distribution of $50 \% .^{14,15}$

The protocol and procedures of the study and the informed consent form (ICF) were submitted to the Institutional Research Review and Ethics Committee of Jazan University, Jazan, Saudi Arabia, for prior approval. Ethics committee approval (Approval no. REC42/1/139) was obtained before starting the study. This study was performed in accordance to the principles of the Helsinki Declaration for studies involving human subjects.

Statistical analysis. Data was analyzed using the Statistical Package for the Social Sciences for Windows, version 23 (IBM Corp., Armonk, NY, USA). Frequencies, total percentages, means, and standard deviations were used to express the socio-demographics of the study sample. Statistically significant associations between the categorical variables were assessed by cross-tabulations with Pearson's Chi-square $\left(\chi^{2}\right)$, while the Fisher's exact test was used for variables having an expected cell count below 5. The multivariable logistic regression model was also used to examine any association between selected sample characteristics/ survey items, with severity of side effects (major/minor) as an outcome variable. An alpha level was set at 0.05 to determine statistical significance.

Results. The socio-demographics of the study participants are depicted in Table 1. A total of 408 participants attempted the survey, of which 9 participants did not agree to the ICF, and 2 responses were found to be incomplete and consequently removed during validation. Therefore, the total number of agreed and validated responses obtained was 397, which was then further analyzed. In this study, the gender distribution among the study sample was almost equal; $52.6 \%$ of the samples were males and $47.4 \%$ were females. More than two-thirds (77.1\%) of the study participants belonged to the age group of 27-36 years, while only $5.8 \%$ were $>47$ years. The study population distribution on the basis of nationality was also similar; $50.6 \%$ were Saudi, while the remaining $49.4 \%$ were non-Saudi. Majority of the study participants (65.5\%) had a bachelor's degree, while only $9.1 \%$ of them had a doctorate. Almost half of the study sample comprised 
Table 1 - Participants' socio-demographics.

\begin{tabular}{lc}
\hline Variable & $\mathbf{n}(\%)$ \\
\hline Exact age, mean \pm SD & $34.43 \pm 6.73$ \\
Gender & \\
Male & $209(52.6)$ \\
Female & $188(47.4)$ \\
Age group (in years) & \\
$27-36$ & $306(77.1)$ \\
$37-46$ & $68(17.1)$ \\
$47-56$ & $23(5.8)$ \\
Nationality & \\
Saudi & $201(50.6)$ \\
Non-Saudi & $196(49.4)$ \\
Education qualification & \\
Bachelors & $260(65.5)$ \\
Masters & $101(25.4)$ \\
PhD & $36(9.1)$ \\
Occupation & \\
Physician & $87(21.9)$ \\
Pharmacist & $178(44.8)$ \\
Nurse & $59(14.9)$ \\
Teacher/preceptor & $22(5.5)$ \\
Other health care professional & $51(12.8)$ \\
&
\end{tabular}

pharmacists (44.8\%), while teachers/preceptors made only $5.5 \%$ of the sample.

Table 2 shows the descriptive statistics of the vaccinerelated side effects, timeline after which side effects were experienced, need for medical assistance, complete recovery after the side effects, and days required to recover. The majority of the study sample reported minor side effects $(59.9 \%$ ), while more than a quarter $(25.7 \%)$ of the sample did not report any vaccinerelated side effects. Comparatively, a meager percentage $(14.4 \%)$ of respondents reported experiencing major vaccine-related side effects. With regard to the minor side effects reported by the participants, more than half of them $(66.4 \%)$ experienced low-grade fever, chills and headache (35.7\%), and pain at the injection site $(30.7 \%)$. Myalgia, arthralgia, general fatigue, and tiredness were the other reported minor side effects. In the sample studied, high-grade fever (above $39^{\circ} \mathrm{C}$; $82.4 \%$ ) was observed to be the main vaccine-related major side effect, followed by dyspnea (14\%) and anxiety $(3.5 \%)$. No serious major side effects were reported by any participant, indicating excellent tolerability of both vaccines. When asked on the time after which the participants experienced the side effects, almost all $(92.2 \%)$ of the side effects were noticed within 24 $\mathrm{h}$ of receiving the vaccine. Moreover, participants did not require medical assistance or hospitalization after experiencing minor side effects, whereas only $12.3 \%$
Table 2 - Descriptive statistics of vaccine related side effects.

\begin{tabular}{lc}
\hline Variables & $\mathbf{n}(\%)$ \\
\hline Severity of vaccine related side effects & \\
Major & $57(14.4)$ \\
Minor & $238(59.9)$ \\
No side effect reported & $102(25.7)$ \\
Minor side effects & \\
Low grade fever, chills \& headache & $85(35.7)$ \\
Pain at the injection site & $73(30.7)$ \\
Myalgia and arthralgia & $33(13.9)$ \\
Fatigue \& tiredness & $47(19.6)$ \\
Major side effects & \\
High grade fever & $47(82.4)$ \\
Dyspnea & $8(14.0)$ \\
Anxiety & $2(3.5)$ \\
Timeline after which the side effects were experienced & \\
$<12$ hours & $23(7.8)$ \\
12-24 hours & $234(79.3)$ \\
$24-48$ hours & $38(12.9)$ \\
Medical assistance due to minor side effects & \\
Yes & $0(0.0)$ \\
No & $238(100)$ \\
Medical assistance due to major side effects & \\
Yes & $7(12.3)$ \\
No & $50(87.7)$ \\
Medication taken to treat minor side effects & \\
Yes & $172(72.2)$ \\
No & $66(27.7)$ \\
Medication taken to treat major side effects & \\
Yes & $57(100)$ \\
No & $0(0.0)$ \\
Yes & \\
No & $7(100)$ \\
Days to recover after medical assistance & $0(0.0)$ \\
1-2 2 & \\
\hline & \\
& \\
\hline &
\end{tabular}

of the 57 participants who reported experiencing major side effects needed medical assistance for their resolution. When asked regarding the medications taken by the participants experiencing minor side effects, $72.3 \%$ reported that they needed to take medication to treat the side effects, while $100 \%$ of the participants experiencing major side effects needed to have medication to treat the side effects. As far as the type of medication was concerned, paracetamol alone or in combination with other agents such as caffeine, ibuprofen, and meloxicam were the drugs of choice for most of the participants experiencing both minor and major side effects. All the participants made a full and complete recovery at the time of the survey. Close to three-quarters $(71.4 \%)$ of the participants who needed medical assistance recovered within 2 days, and 
the remaining respondents took more than 2 days to recover.

To study the association between participants' socio-demographics and other sample characteristics and severity of side effects, cross-tabulations using Pearson's Chi-square test and Fisher's exact test were applied, and the level of significance was determined in each case (Table 3). In the present study it was noted that $70.2 \%$ of female participants reported minor side effects while $22.9 \%$ of them reported major side effects and only $6.9 \%$ did not report any side effects. Whereas, $42.6 \%$ of male participants did not show any side effects $\left(\chi^{2}=73.32 ; p<0.001\right)$. In the age group
27-36 years, more than half of participants $(60.2 \%)$ reported minor side effects, $15.0 \%$ exhibited major side effects and $22.9 \%$ did not show any side-effect. Similarly, in the age group of 46-57 years, majority of respondents $(65.2 \%)$ reported minor side effects, while none experienced major side effects $\left(\chi^{2}=10.19 ; p<0.05\right)$, thereby indicating that the presence and severity of side effects decreased with increasing age of the participants. With regards to the nationality of the participants, just over half $(56.7 \%)$ of the Saudis reported minor side effects while only $8.5 \%$ reported major side effects whereas, $20.4 \%$ of the non-Saudi participants reported major side effects $\left(\chi^{2}=23.78 ; p<0.001\right)$.

Table 3 - Cross tabulations of the severity of side effects with sample characteristics.

\begin{tabular}{|c|c|c|c|c|c|}
\hline Variables & No side effect reported & Minor & Major & Chi-square $\left(\chi^{2}\right)$ & $P$-value \\
\hline \multicolumn{6}{|l|}{ Gender } \\
\hline $\begin{array}{l}\text { Male } \\
\text { Female }\end{array}$ & $\begin{array}{l}89(42.6) \\
13(6.9)\end{array}$ & $\begin{array}{l}106(50.7) \\
132(70.2)\end{array}$ & $\begin{array}{c}14(6.7) \\
43(22.9)\end{array}$ & 73.32 & $<0.001$ \\
\hline \multicolumn{6}{|l|}{ Age group (in years) } \\
\hline $\begin{array}{l}27-36 \\
37-46 \\
47-56\end{array}$ & $\begin{array}{l}70(22.9) \\
24(35.3) \\
8(34.8)\end{array}$ & $\begin{array}{l}190(62.1) \\
33(48.5) \\
15(65.2)\end{array}$ & $\begin{array}{c}46(15.0) \\
11(16.2) \\
0(0.0)\end{array}$ & 10.19 & $0.03^{*}$ \\
\hline \multicolumn{6}{|l|}{ Nationality } \\
\hline $\begin{array}{l}\text { Saudi } \\
\text { Non-Saudi }\end{array}$ & $\begin{array}{l}70(34.8) \\
32(16.3)\end{array}$ & $\begin{array}{l}114(56.7) \\
124(63.3)\end{array}$ & $\begin{array}{l}17(8.5) \\
40(20.4)\end{array}$ & 23.80 & $<0.001$ \\
\hline \multicolumn{6}{|l|}{ Educational qualification } \\
\hline $\begin{array}{l}\text { Bachelors degree } \\
\text { Masters degree } \\
\text { Doctorate }\end{array}$ & $\begin{array}{l}65(25.0) \\
24(23.8) \\
13(36.1)\end{array}$ & $\begin{array}{l}156(60.0) \\
66(65.3) \\
16(44.4)\end{array}$ & $\begin{array}{l}39(15.0) \\
11(10.9) \\
7(19.4)\end{array}$ & 5.22 & 0.27 \\
\hline \multicolumn{6}{|l|}{ Occupation } \\
\hline $\begin{array}{l}\text { Physician } \\
\text { Pharmacist } \\
\text { Nurse } \\
\text { Other HCP }\end{array}$ & $\begin{array}{l}26(30.2) \\
37(21.6) \\
18(32.1) \\
21(25.0)\end{array}$ & $\begin{array}{l}52(60.5) \\
113(66.1) \\
27(48.2) \\
46(54.8)\end{array}$ & $\begin{aligned} 8 & (9.3) \\
21 & (12.3) \\
11 & (19.6) \\
17 & (20.2)\end{aligned}$ & 10.60 & 0.10 \\
\hline \multicolumn{6}{|l|}{ Type of vaccine } \\
\hline $\begin{array}{l}\text { Covishield (Oxford-AstraZeneca) } \\
\text { Pfizer (Pfizer BioNTech) }\end{array}$ & $\begin{array}{l}34(11.7) \\
68(64.2)\end{array}$ & $\begin{array}{l}208(71.5) \\
30(28.3)\end{array}$ & $\begin{array}{c}49(16.8) \\
8(7.5)\end{array}$ & 112.08 & $<0.001$ \\
\hline \multicolumn{6}{|l|}{ Comorbidities/current medical condition } \\
\hline $\begin{array}{l}\text { Diabetes } \\
\text { Hypertension/cardiac disorders } \\
\text { Others } \\
\text { No serious medical condition }\end{array}$ & $\begin{array}{l}4(30.8) \\
7(43.8) \\
7(21.2) \\
84(25.1)\end{array}$ & $\begin{array}{c}8(61.5) \\
7(43.8) \\
22(66.7) \\
201(60.0)\end{array}$ & $\begin{array}{c}1(7.7) \\
2(12.5) \\
4(12.1) \\
50(14.9)\end{array}$ & 3.68 & $0.72^{*}$ \\
\hline \multicolumn{6}{|l|}{ Known allergies } \\
\hline $\begin{array}{l}\text { No allergies } \\
\text { Allergies present }\end{array}$ & $\begin{array}{c}96(27.8) \\
6(11.5)\end{array}$ & $\begin{array}{l}223(64.6) \\
15(28.8)\end{array}$ & $\begin{array}{c}26(7.5) \\
31(59.6)\end{array}$ & 99.69 & $<0.001$ \\
\hline \multicolumn{6}{|l|}{ Current medications } \\
\hline $\begin{array}{l}\text { Currently not on any } \\
\text { medications } \\
\text { Currently taking medications }\end{array}$ & $\begin{array}{l}77(21.5) \\
25(64.1)\end{array}$ & $\begin{array}{c}232(64.8) \\
6(15.4)\end{array}$ & $\begin{array}{l}49(13.7) \\
8(20.5)\end{array}$ & 40.30 & $<0.001$ \\
\hline \multicolumn{6}{|l|}{ Previous COVID-19 infection } \\
\hline $\begin{array}{l}\text { Yes } \\
\text { No }\end{array}$ & $\begin{array}{l}95(27.1) \\
7(14.9)\end{array}$ & $\begin{array}{l}209(59.7) \\
29(61.7) \\
\end{array}$ & $\begin{array}{l}46(13.1) \\
11(23.4)\end{array}$ & 5.49 & 0.06 \\
\hline
\end{tabular}


Interestingly, educational qualification, occupation, presence of comorbidities, and previous COVID-19 infection did not yield any statistically significant association with the presence and severity of vaccinerelated side effects, further indicating the safety of vaccines even in patients with underlying medical conditions. In this study, several participants (15.6\%) reported to have diabetes (3.3\%), cardiac disorders (4\%), and respiratory disorders $(8.3 \%)$ as serious underlying medical conditions. However, the comorbidities had a non-significant association with the presence and severity of side effects as compared with the participants who did not have any serious medical condition. Out of the 397 respondents, 47 reported to have had the COVID-19 infection at least 6 months before taking the vaccine and had completely recovered from the infection. No significant associations were found between the percentages of respondents showing side effects with or without previous COVID-19 infection.

However, an important finding of this study was that a very high proportion $(71.5 \%)$ of participants who took Oxford-AstraZeneca Covishield vaccine reported minor vaccine-related side effects and $16.8 \%$ reported major vaccine-related side effects. Whereas, those participants taking Pfizer vaccine a very high percentage $(64.2 \%)$ did not report any vaccine-related side effect $\left(\chi^{2}=112.08 ; p<0.001\right)$. The findings of the current study also showed that participants receiving Covishield vaccine as compared with the Pfizer vaccine reported more major as well as minor vaccine-related side effects, thus yielding a statistically significant association. A significant association was also found between known allergies of the participants and the severity of side effects. More than half of the sample studied (59.6\%) who experienced major vaccine-related side effects had known food or drug-related allergies, while only $7.5 \%$ of the sample with no allergies reported major vaccinerelated side effects $\left(\chi^{2}=99.69 ; p<0.001\right)$. This association meant that allergies and vaccine-related side effects might be inter-related. If a person has known allergies for any product, he/she might be more susceptible to experiencing vaccine-related side effects in comparison with those individuals without any known allergies. In this study, $13.1 \%$ participants reported to have allergy from nuts, dust, soya, and penicillin. A considerably small percentage of respondents $(20.5 \%)$ currently on medications reported presence of major vaccine-related side effects $\left(\chi^{2}=40.30 ; p<0.001\right)$ (Table 3$)$.

The multivariable logistic regression model was used to examine any association between selected sample characteristics and the severity of any side effects as an outcome variable (Table 4). For the sake of carrying out
Table 4 - Binary logistic regression between severity of side effects and selected variables.

\begin{tabular}{|c|c|c|c|c|}
\hline \multirow[t]{2}{*}{ Determinants } & \multirow[t]{2}{*}{ AOR } & \multicolumn{2}{|c|}{$95 \% \mathrm{CI}$} & \multirow[t]{2}{*}{$P$-value } \\
\hline & & Lower & Upper & \\
\hline \multicolumn{5}{|l|}{ Gender } \\
\hline $\begin{array}{l}\text { Male } \\
\text { Female }\end{array}$ & 3.72 & 1.79 & 7.75 & $\begin{array}{l}<0.001 \\
\text { Ref }\end{array}$ \\
\hline \multicolumn{5}{|c|}{ Name of the vaccine } \\
\hline $\begin{array}{l}\text { Covishield } \\
\text { Pfizer }\end{array}$ & 1.07 & 0.43 & 2.65 & $\begin{array}{l}0.89 \\
\text { Ref }\end{array}$ \\
\hline \multicolumn{5}{|l|}{ Known allergies } \\
\hline $\begin{array}{l}\text { Yes } \\
\text { No }\end{array}$ & 16.29 & 7.76 & 34.17 & $\begin{array}{c}<0.001 \\
\operatorname{Ref}\end{array}$ \\
\hline \multicolumn{5}{|l|}{ Nationality } \\
\hline $\begin{array}{l}\text { Saudi } \\
\text { Non-Saudi }\end{array}$ & 2.51 & 1.24 & 5.09 & $\begin{array}{c}0.01 \\
(p<0.05) \\
\text { Ref }\end{array}$ \\
\hline
\end{tabular}

CI: confidence interval, AOR: adjusted odds ratio, ref: reference category

the binary logistic regression, the severity of vaccinerelated side effects was converted into a binary variable by clubbing no reported vaccine-related side effect with minor vaccine-related side effect as one variable and the major vaccine-related side effects as the other variable. It was observed that females were 3.72 times more likely to have major vaccine-related side effects compared to males (adjust odd ratio [AOR]: 3.72; 95\% CI: [1.79-7.75]; $p<0.001)$. The study participants with known allergies were 16.29 times more likely to develop major vaccine-related side effects than those who did not have any known allergies (AOR: 16.29; 95\% CI: [7.76-34.17]; $p<0.001)$. With regard to nationality, Saudis reported 0.40 times less presence of having major vaccine-related side effects than non-Saudis (AOR: 0.40; 95\% CI: [0.20-0.81]; $p<0.05$ ).

Discussion. As of early October, Saudi Arabia had already administered more than 23,573,510 doses of vaccines $(66.7 \%$ of the population) out of the $34,813,867$ population. ${ }^{16}$ The vaccine metrics include nearly 1.53 vaccinations/second (approximately 131,874 doses/day) at a rate of 121.60 doses per 100 people. The amazing rate at which this vaccination drive is going on not only shows its efficiency and effectiveness but also demonstrates the widespread acceptability of the program. ${ }^{17}$ At this rate, Saudi Arabia is expected to vaccinate $70 \%$ of its population by November 25, 2021. However, the misconstrued perceptions toward vaccines developed for COVID-19 are not good for few people, and they still are showing 
reluctancy and unacceptability for the vaccines. ${ }^{18}$ Fast-track development of COVID-19 vaccines has led a tiny proportion of the population to doubt the safety of the vaccines, if not their efficacy.

Widespread rumors and misconceptions on the vaccines worldwide have created unwarranted hindrances for many governments across the world to effectively carry out their vaccination drives. Recent reports of some "vaccine-induced COVID-19 mimicry" syndromes causing serious adverse events, such as thromboembolic events/blood clots associated with the Oxford-AstraZeneca and Johnson \& Johnson vaccines, have also not helped the cause; some European countries have even suspended using the vaccines due to increased incidences of vaccine-related adverse events in their countries. ${ }^{19}$ In the United Kingdom, 309 out of 33 million people who received the AstraZeneca vaccine were reported to develop blood clots, out of which 56 patients died. In Europe, 142 people developed blood clots out of 16 million people. Saudi-FDA also confirmed 34 cases of blood clots or thrombosis along with low blood platelet counts in people receiving the Oxford-AstraZeneca vaccine. These untoward reactions and unfortunate incidences of vaccine-related adverse events have further created some sort of fear toward vaccines. Governments are taking initiatives to tackle these problems and create general awareness toward the many benefits of becoming vaccinated.

Saudi Arabia is one of the countries where low incidence of newly detected COVID-19 cases and associated mortality rates vibrantly highlight the extensive popularity, acceptability, and compliance to the various preventative measures that have been implemented by the Saudi Ministry of Health $(\mathrm{MOH})$ to curb the spread of COVID-19 infections. ${ }^{20}$ The introduction of widely accepted and used mobile applications such as Tawakkalna, Mawid, Tabaud, and Sehaty by the Saudi $\mathrm{MOH}$ in close cooperation and collaboration with the Saudi Data and Artificial Intelligence Authority has helped in creating wideranging public health awareness, enabling contact tracing, booking appointments, and providing web-based consultations. ${ }^{21}$ These prompt, efficient initiatives undertaken by the Saudi $\mathrm{MOH}$ have gone a long way in Saudi Arabia being among those very few countries with low COVID-19-related mortality rates. ${ }^{20}$ The use of mobile application "Sehaty" for registration to receive vaccinations has already been highlighted and is widely used by the Saudi population. ${ }^{18}$ With the ease of use and popularity of the initiatives taken by the Saudi $\mathrm{MOH}$ in vaccine registrations and on the basis of number of doses given so far, we can fervently state that the vaccination drive undertaken by the Saudi $\mathrm{MOH}$ has not only been exceedingly popular but also has acquired wide-ranging acceptability among the Saudi citizens and residents due to its user-friendly nature. People living in rural areas, uneducated people, elderly, and those not having access to proper internet or do not know how to use these mobile applications are being encouraged to partake in educational initiatives with the aim of teaching these vulnerable groups the benefits of these applications and ways of accessing and using them.

Some of the strengths of the present study include identification of presence of COVID-19 vaccine-related side effects among HCPs and to have compared the safety of the 2 widely used vaccines in the Kingdom of Saudi Arabia.

Study limitations. The study did not include analyzing the presence of COVID-19 vaccine-related side effects on the general population and did not examine the safety of other vaccines apart from the Oxford-AstraZeneca and Pfizer vaccines. The cross-sectional study design did not allow the causal relationship between the variables to be assessed. An online survey would place those individuals not having access to internet or social media at a disadvantage of participating in the survey and recording their responses. As this study is a self-administered survey, the responses will almost always be subject to recall bias. The participants were not restricted to one response each, which might lead to the overestimation of the presence of side effects.

In conclusion, the present study reported presence of minor side effects mainly after receiving either of the 2 vaccines, Pfizer BioNTech and AstraZeneca. However, the presence and severity were observed to be more with the latter. Major side effects included high-grade fever for both vaccines and no serious adverse events were reported by any of the participants. This study further confirms the safety of both the vaccines and the present data can be used in creating awareness among the individuals who are reluctant to be vaccinated.

Further studies are nevertheless warranted on larger and wider population to establish the association of vaccine-related side effects with various medical and non-medical factors which could further clarify the misconceptions regarding the COVID-19 vaccines.

Acknowledgment. The authors gratefully acknowledge the Pharmacy Practice Research Unit, Department of Clinical Pharmacy, and College of Pharmacy for the support and encouragement in carrying out this research. We are also thankful to Mohammed A. Ayyashi, Pharmacist, Armed Forces Hospital, Jazan, Kingdom of Saudi 
Arabia; and Pharm. D. students Hani Mohammed Thobab, Thamer Mohammed Marei, Abdulwahab A. Bajawi, and Riyadh Deafallah Rahmani at College of Pharmacy, Jazan University, Jazan, Kingdom of Saudi Arabia, for their assistance in data collection. We would also like to thank KG Support Limited, Hong Kong for English language editing. We are also grateful to the respondents who have participated in this study in spite of the difficult times during COVID-19.

\section{References}

1. Syed NK, Griffiths MD. Nationwide suicides due to alcohol withdrawal symptoms during COVID-19 pandemic: a review of cases from media reports. J Psychiatr Res 2020; 130: 289-291.

2. Mamun MA, Syed NK, Griffiths MD. Indian celebrity suicides before and during the COVID-19 pandemic and their associated risk factors: evidence from media reports. J Psychiatr Res 2020; 131: 177-179.

3. Han E, Tan MMJ, Turk E, Sridhar D, Leung GM, Shibuya K, et al. Lessons learnt from easing COVID-19 restrictions: an analysis of countries and regions in Asia Pacific and Europe. Lancet 2020; 396: 1525-1534.

4. Xing K, Tu XY, Liu M, Liang ZW, Chen JN, Li JJ, et al. Efficacy and safety of COVID-19 vaccines: a systematic review. Zhongguo Dang Dai Er Ke Za Zhi 2021; 23: 221-228.

5. Forni G, Mantovani A. COVID-19 vaccines: where we stand and challenges ahead. Cell Death Differ 2021; 28: 626-639.

6. Hunter PR. Thrombosis after covid-19 vaccination. BMJ 2021; 373: n958.

7. Wise J. Covid-19: European countries suspend use of OxfordAstraZeneca vaccine after reports of blood clots. BMJ 2021; 372: n699.

8. Saudi Food \& Drug Authority. COVID vaccine adverse event. SFDA; [Updated 2021; accessed 2021 March]. Available from: https://ade.sfda.gov.sa/Covid/CovidRequest?AspxAutoDetectC ookieSupport $=1$

9. Centers for Disease Control and Prevention. Vaccine adverse event reporting system (VAERS). CDC; [Updated 2021; accessed 2021 March]. Available from: https://www.cdc.gov/ coronavirus/2019-ncov/vaccines/safety/vaers.html

10. Almanasreh E, Moles R, Chen TF. Evaluation of methods used for estimating content validity. Res Social Adm Pharm 2019; 15: $214-221$.
11. Elnaem MH, Kamarudin NH, Syed NK, Huri HZ, Dehele IS, Cheema E. Associations between socio-demographic factors and hypertension management during the COVID-19 pandemic: preliminary findings from Malaysia. Int J Environ Res Public Health 2021; 18: 9306.

12. Beaton DE, Bombardier C, Guillemin F, Ferraz MB. Guidelines for the process of cross-cultural adaptation of self-report measures. Spine (Phila Pa 1976) 2000; 25: 3186-3191.

13. Syed NK, Syed MH, Meraya AM, Albarraq AA, Al-Kasim MA, Alqahtani $S$, et al. The association of dietary behaviors and practices with overweight and obesity parameters among Saudi university students. PLoS One 2020; 15: e0238458.

14. RaoSoft. Sample size calculator. [Updated 2004; accessed 2021 March]. Available from: http://www.raosoft.com/samplesize. html

15. Tripathi R, Alqahtani SS, Albarraq AA, Meraya AM, Tripathi P, Banji D, et al. Awareness and preparedness of COVID-19 outbreak among healthcare workers and other residents of South-West Saudi Arabia: a cross-sectional survey. Front Public Health 2020; 8: 482.

16. Ministry of Health. Saudi Health Council, COVID-19 dashboard. MOH; [Updated 2021; accessed 2021 October]. Available from: https://covid19.moh.gov.sa/

17. Covidvax live. Live COVID-19 vaccination tracker: Saudi Arabia. [Updated 2021; accessed 2021 October]. Available from: https://covidvax.live/location/sau

18. Almaghaslah D, Alsayari A, Kandasamy G, Vasudevan R. COVID-19 vaccine hesitancy among young adults in Saudi Arabia: a cross-sectional web-based study. Vaccines (Basel) 2021; 9: 330.

19. Dotan A, Shoenfeld Y. Perspectives on vaccine induced thrombotic thrombocytopenia. J Autoimmun 2021; 121: 102663.

20. Banjar WM, Alaqeel MK. Healthcare worker's mental health dilemma during COVID-19 pandemic: a reflection on the KSA experience. J Taibah Univ Med Sci 2020; 15: 255-257.

21. Alanzi T. A review of mobile applications available in the app and google play stores used during the COVID-19 outbreak. J Multidiscip Health 2021; 14: 45-57. 


\section{STUDY QUESTIONNAIRE}

\section{Post-vaccination survey for monitoring the side effects of COVID-19 vaccines among Healthcare Professionals of Jazan Province, Saudi Arabia}

\section{Informed Consent Form (ICF)}

Kindly please read the following points carefully before starting the survey and select "Agree" if you want to continue. Kindly please select "Do Not Agree" in case you do not agree to any of the following points.

$>$ This survey is aimed at assessing the prevalence and severity of vaccine related side effects.

$>$ This survey consists of questions related to the type and severity of side effects due to COVID-19 and should take less than 10 minutes to complete.

$>$ Confidentiality is maintained throughout the survey as there will not be any question asking your identity or personal information.

$>$ This data obtained from the survey will only be used for scientific purpose.

This survey is meant only for healthcare professionals working in Academic and Healthcare sectors of Jazan province, Saudi Arabia.

$>$ This survey is for participants who are above 26 years of age and are vaccinated with one or two doses of any vaccine for COVID-19.

I confirm that I have read all the aforementioned information regarding this survey and AGREE to fill the questionnaire with my own freewill without any external pressure or influence. 
SECTION - 1: SOCIO-DEMOGRAPHICS

\begin{tabular}{|c|c|c|}
\hline Variable & Options & Tick Here \\
\hline \multirow{2}{*}{ D1: Gender } & Male & $\square$ \\
\hline & Female & $\square$ \\
\hline \multirow{4}{*}{ D2: Age Group (in years) } & $27-36$ & $\square$ \\
\hline & $37-46$ & $\square$ \\
\hline & $47-56$ & $\square$ \\
\hline & $>57$ & $\square$ \\
\hline D3: Exact Age (in years) & 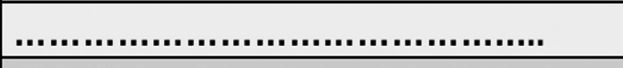 & \\
\hline \multirow{2}{*}{ D4: Nationality } & Saudi & $\square$ \\
\hline & Non - Saudi & $\square$ \\
\hline \multirow{3}{*}{ D5: Education Qualification } & Bachelors & $\square$ \\
\hline & Masters & $\square$ \\
\hline & $\mathrm{PhD}$ & $\square$ \\
\hline \multirow{5}{*}{ D6: Occupation } & Physician & $\square$ \\
\hline & Pharmacist & $\square$ \\
\hline & Nurse & $\square$ \\
\hline & Teacher/Preceptor & $\square$ \\
\hline & Other Health Care Professional & $\square$ \\
\hline
\end{tabular}


SECTION - 2: SAMPLE CHARACTERISTICS

\begin{tabular}{|c|c|c|c|c|}
\hline \multicolumn{3}{|c|}{ 1. Do you have any known allergies with specific substances? } & No $\square$ & Yes $\square$ \\
\hline \multicolumn{5}{|c|}{ If Yes, kindly specify: } \\
\hline \multicolumn{5}{|c|}{ 2. Do you have any of the following medical conditions } \\
\hline \multicolumn{3}{|c|}{$>$ Hypertension } & No $\square$ & Yes $\square$ \\
\hline \multicolumn{3}{|l|}{$>$ Diabetes Mellitus } & No $\square$ & Yes $\square$ \\
\hline \multicolumn{3}{|l|}{$>$ Cardiac Disorders } & No $\square$ & Yes $\square$ \\
\hline \multicolumn{3}{|l|}{$>$ Respiratory Disorders } & No $\square$ & Yes $\square$ \\
\hline \multicolumn{3}{|l|}{$>$ Renal Disorders } & No $\square$ & Yes $\square$ \\
\hline \multicolumn{3}{|l|}{$>$ Liver Disorders } & No $\square$ & Yes $\square$ \\
\hline \multicolumn{3}{|l|}{$>$ No Serious Medical Condition } & No $\square$ & Yes $\square$ \\
\hline \multicolumn{3}{|l|}{ 3. Are you currently on any medications? } & No $\square$ & Yes $\square$ \\
\hline \multicolumn{5}{|c|}{ If Yes, kindly specify: } \\
\hline \multicolumn{3}{|c|}{ 4. Did you have any prior COVID-19 infection? } & No $\square$ & Yes $\square$ \\
\hline \multicolumn{5}{|c|}{ If Yes, kindly specify when: } \\
\hline \multicolumn{5}{|c|}{ 5. Which COVID-19 vaccination did you receive? } \\
\hline \multicolumn{3}{|c|}{$>$ COVISHIELD (Oxford-AstraZeneca Vaccine) } & No $\square$ & Yes $\square$ \\
\hline \multicolumn{3}{|c|}{$>$ PFIZER (Pfizer-BioNTech Vaccine) } & No $\square$ & Yes $\square$ \\
\hline \multicolumn{3}{|c|}{ 6. How many doses of the vaccine have you received so far? } & One $\square$ & Two $\square$ \\
\hline \multicolumn{3}{|c|}{$\begin{array}{l}\text { 7. In case of experiencing any side effects after which dose did } \\
\text { you experience them? }\end{array}$} & First $\square$ & Second $\square$ \\
\hline $\begin{array}{l}\text { 8. In case of experiencing any side } \\
\text { effects after how much time of taking } \\
\text { the vaccine did you experience them? }\end{array}$ & $\begin{array}{c}\text { Within } 12 \mathrm{H} \\
\square\end{array}$ & $\begin{array}{c}12-24 \mathrm{H} \\
\square\end{array}$ & $\begin{array}{c}24-48 \mathrm{H} \\
\square\end{array}$ & $\begin{array}{c}\text { After } 48 \mathrm{H} \\
\square\end{array}$ \\
\hline $\begin{array}{l}\text { 9. What is the severity of the side } \\
\text { effects that you experienced? }\end{array}$ & \multicolumn{2}{|c|}{ No Side effects reported } & $\begin{array}{l}\text { Minor Side } \\
\text { effects } \\
\text { reported } \square\end{array}$ & $\begin{array}{c}\text { Major } \\
\text { Side effects } \\
\text { reported } \square\end{array}$ \\
\hline \multicolumn{5}{|l|}{ 10. Minor side effects (Tick all that apply) } \\
\hline \multicolumn{3}{|l|}{$>$ Low grade fever $\left(\right.$ Below $\left.39^{\circ} \mathrm{C}\right)$} & No $\square$ & Yes $\square$ \\
\hline \multicolumn{3}{|l|}{$>$ Pain at injection site } & No $\square$ & Yes $\square$ \\
\hline \multicolumn{3}{|l|}{$>$ Inflammation at the site of injection } & No $\square$ & Yes $\square$ \\
\hline \multicolumn{3}{|l|}{$>$ Headache } & No $\square$ & Yes $\square$ \\
\hline \multicolumn{3}{|l|}{$>$ Body ache / Pain in joints } & No $\square$ & Yes $\square$ \\
\hline \multicolumn{3}{|l|}{$>$ Myalgia } & No $\square$ & Yes $\square$ \\
\hline \multicolumn{3}{|l|}{$>$ Tiredness/Fatigue } & No $\square$ & Yes $\square$ \\
\hline \multicolumn{3}{|l|}{$>$ Skin rashes } & No $\square$ & Yes $\square$ \\
\hline \multicolumn{3}{|l|}{$>$ Diarrhea } & No $\square$ & Yes $\square$ \\
\hline Nausea \& Vomiting & & & No $\square$ & Yes $\square$ \\
\hline$>$ Others (If 'Yes' kindly specify) & & & No $\square$ & Yes $\square$ \\
\hline
\end{tabular}




\begin{tabular}{|c|c|c|}
\hline \multicolumn{3}{|l|}{ 12. Major side effects (Tick all that apply) } \\
\hline$>$ Seizures / Convulsions & No $\square$ & Yes $\square$ \\
\hline$D$ Dyspnea & No $\square$ & Yes $\square$ \\
\hline$>$ Anxiety & No $\square$ & Yes $\square$ \\
\hline$>$ High grade fever (Above $39^{\circ} \mathrm{C}$ ) & No $\square$ & Yes $\square$ \\
\hline Loss of consciousness & No $\square$ & Yes $\square$ \\
\hline Anaphylaxis & No $\square$ & Yes $\square$ \\
\hline$>$ Blood Clot & No $\square$ & Yes $\square$ \\
\hline$>$ Thrombocytopenia & No $\square$ & Yes $\square$ \\
\hline$>$ Others (If 'Yes' kindly specify) & No $\square$ & Yes $\square$ \\
\hline $\begin{array}{l}\text { 13. Did you require medical assistance/hospitalization because of } \\
\text { any of these side effects? }\end{array}$ & No $\square$ & Yes $\square$ \\
\hline \multicolumn{3}{|l|}{ If Yes, kindly specify for how many days? } \\
\hline \multicolumn{3}{|l|}{ 14. Have you recovered fully? } \\
\hline 15. How long did it take for a full recovery & 1 - 2 Days & $>2$ Days \\
\hline
\end{tabular}

THANK YOU VERY MUCH INDEED FOR YOUR TIME 